\title{
Do cosmetic products which Terlemeyi önleyen kozmetik are prevent sweating cause ürünler meme kanserine mi breast cancer? $^{1}$ neden oluyor?
}

\author{
Sevil Güler Demir ${ }^{2}$ \\ Hülya Bulut ${ }^{3}$
}

\begin{abstract}
Today, underarm and antiperspirant deodorants are extensively consumed cosmetic products in order to prevent sweating. Increasing use of these products is revived the claims of increasing of breast cancer risk. While discussing these claims, drawn attention at society, in the popular press and on the Internet, it has begun to discuss in the scientific literature at the same time. There are academic studies which are shown the relation between underarm cosmetic products and breast cancer as well as the opposites. In this article, literature about whether there is relationship between underarm cosmetic products and breast cancer is reviewed and obtained findings are explained.
\end{abstract}

Keywords: Underarm cosmetic products; deodorants; antiperspirants; breast cancer; breast cancer risk.

(Extended English abstract is at the end of this document)

\section{Özet}

Günümüzde koltuk altı ve antiperspirant deodorantlar terlemeyi önlemek amaciyla yaygin olarak kullanılan kozmetik ürünlerdir. $\mathrm{Bu}$ ürünlerin kullanımının artması, özellikle meme kanseri riskini artturdığ1 iddialarını gündeme getirmiștir. Toplumun ilgisini de çeken bu iddialar popüler basin ve internet üzerinde tartışlırken, aynı zamanda bilimsel literatürde de tartışılmaya başlamıştır. Literatürde koltuk altı kozmetik ürünlerle meme kanseri arasında ilişki olduğunu belirten çalışmaların yanı sıra ilişki olmadığını gösteren çalışmalar da yer almaktadır. $\mathrm{Bu}$ makalede, koltuk altı kozmetik ürünlerle meme kanseri arasında ilişki olup olmadığına ilişkin literatür taranmış ve elde edilen bulgular açılanmıştır.

AnahtarKelimeler: Koltuk altı kozmetik ürünler; deodorantlar; antiperspirant deodorantlar; meme kanseri, meme kanseri riski

\footnotetext{
${ }^{1}$ The part of this paper has been to presented as an oral presentation at the VIII. National Breast Diseases Congress, 21-25 September, 2005, Istanbul, Turkey.

2RN.,Ph.D., Instructor, Gazi University, Faculty of HealthSciences, Department of Nursing,sevilgulerdemir@yahoo.com ${ }^{3}$ RN.,Ph.D., AssociateProfessor, Gazi University, Faculty of HealthSciences, Department of Nursing, hulyadenizbulut@gmail.com
} 
GülerDemir, S., \&Bulut, H. (2016). Terlemeyiönleyenkozmetikürünler meme kanserine mi nedenoluyor?International Journal of Human Sciences, 13(1), 309-317. doi: $10.14687 /$ ijhs.v13i1.3345

\section{Giriş}

Günümüzde kadınların korkulu rüyası olan meme kanserinin görülme sıklı̆̆1 hızla artış göstermektedir (Beji \& Reis, 2007; Özmen, 2009; Sezer, Yılmaz, Gurler, \& Koyuncu, 2011; Özmen, 2013; International Agency for Research on Cancer,2014). Epidemiyolojik araştırmalar meme kanserinin büyük kısmının (\%90) çevresel kaynaklı olduğunu ve özellikle batı kültürüne göre sürdürülen yaşam biçiminin bunda etkili olduğunu göstermesine karşın, meme kanserine neden olan özellikli ajanların ne olduğu kesin olarak bilinmemektedir (Darbre, 2001; Onat ve Başaran 2003). Son yıllarda yapılan araştırmalarda, BRCA 1 ve BRCA 2 tümör baskılayıcı genlerdeki mutasyonların meme kanserine neden olduğu belirtilirken, ailedeki meme kanseri öyküsünün \%5-10 oranında etkili olduğu bildirilmektedir (Darbre 2001; Onat \& Başaran 2003; Belli \&Ferahman, 2011). Erken menarş, geç menopoz, doğum yapmama, ilk doğumunu geç yaşta yapma, oral kontraseptif kullanma ve hormon replasman tedavisi alma meme kanseri ile ilgili tanımlanmış risk faktörleri arasında sıralanmaktadır. Diyet, fiziksel aktivite, sigara ve alkol kullanımı da meme kanseri için çok düşük risk oluşturan diğer faktörler olarak bilinmektedir (Darbre 2001; Beji \& Reis, 2007; Sezer ve ark., 2011; Dieterich, Stubert, Reimeri Ericson, \&Berling, 2014). Bununla birlikte, meme kanserine neden olan diğer ajanların ne olduğunun tam olarak açıklığa kavuşturulamadığı, bilinen tüm etiyolojik nedenlerin meme kanserini oluşturan toplam nedenlerin sadece \%40'ina tekabül ettiği belirtilmektedir(Darbre, 2001; Belli \&Ferahman, 2011).

Literatürde, meme kanserinin gelişmesine neden olan etkenlerden biri olarak koltuk altı kozmetik ürünlerinin kullanımı gösterilmektedir. Son yıllarda bu ürünlerin kullanımının yaygınlaşmasına paralel olarak meme kanseri insidansının giderek artması ve meme kanserinin sıklikla memenin üst dış kadranında görülmesi, bu ürünlerin özellikle meme kanseri riskini arttırdığı iddialarını gündeme getirmiştir (Jones 2000; Darbre 2001; Dieterich ve ark., 2014). Bu makalede bilim çevrelerinde tartışılan koltuk altı ürün kullanımı ile meme kanseri riski hakkında okuyucuların dikkatinin çekilmesi amaçlanmıştır.

Makale hazırlanırken Google Akademik, Medline ve Pubmed tarama motorları kullanılmıştır. Anahtar kelime olarak "deodorant ve meme kanseri ya da meme neoplasm ya da meme karsinomu" kullanılmıştur. Google Akademi'de 2960, Medline'da 83 ve Pubmed'de 11 makaleye ulaşılmıştır. Bu makalede sistematik bir tarama yapılmamıs, sadece bu konu üzerine literatüre temel oluşturan çalışmalara yer verilmeye çalışılmıstır.

\section{Terlemeyi Önleyen Kozmetik Ürünler ve Meme Kanseri Riski}

Literatürde, koltuk altı ve antiperspirant deodorantların terlemeyi önlemek amaciyla kullanilan kozmetik ürünler olduğu belirtilmektedir. Öncelikle bu ürünlerin terlemeyi nasıl önlediğini anlamak gerekmektedir. Koltuk altı deodorantlantn stik, roll-on ve krem formülleri bulunmakta olup, bu formüllerin içeriğinde antimikrobiyal koruyucular ( $\mathrm{p}$-hydroxybenzoic asit esterleri) bulunmaktadır. $\mathrm{Bu}$ antimikrobiyal koruyucular, vücut yüzeyindeki bakteriyel büyümeyi engelleyerek ter kokusunun oluşmasını önlemektedir(Darbre, 2001). Antiperspirant deodorantlar ise, içerdikleri alüminyum tuzlarının çökelmesi ve zarar görmüş hücrelerle birleşmesi sonucu oluşan fiziksel bir tupa (antiperspirant deodorantların içindeki alüminyum tuzlanı koltuk altındaki hücrelerle birleşip çökelerek bir tıpa oluşturur) gibi görev yaparak koltuk altı bölgesindeki ter kanallarını bloke etmekte ve terin vücut yüzeyine çıkmasını önlemektedir (Darbre, 2001; Darbre, 2005a). Buna ek olarak, deri yüzeyinde kalan alüminyum tuzları, sabun ya da şampuan ile yıkanmadığ1 sürece etki etmeye devam etmektedir. Bilindiği gibi, koltuk altı bölgesinin jilet ile tıraş edilmesi küçük kesilere ve aşınmalara neden olmaktadır. Böyle bir uygulama sonrası antiperspirant deodorant kullanıldığında, deodorantın içerdiği kimyasal maddelerin vücuda girişinin kolaylaştığı belirtilmektedir(Darbre, 2005a).

Yukarıda da belirtildiği gibi, koltuk altı kozmetik ürünler ya tıkaç gibi etki ederek ya da bakterilerin büyümesini engelleyerek terlemeyi önlemektedir. Koltuk altı kozmetik ürünlerin kullanımı çok 
GülerDemir, S., \&Bulut, H. (2016). Terlemeyiönleyenkozmetikürünler meme kanserine mi nedenoluyor?International Journal of Human Sciences, 13(1), 309-317. doi: $10.14687 /$ ijhs.v13i1.3345

tercih edilmesine rağmen, literatür incelendiğinde bazı çalısmalarda koltuk altı kozmetik ürünlerin kullanımı ile meme kanseri arasında ilişki olduğu belirtilirken, diğer çalışmalarda bu görüş çürütülmeye çalışılmaktadır.

Özellikle çalışmalarda antiperspirant deodorantların uygulandığı alanın memeye yakın olduğu ve bunun da memenin üst diş kadranındaki meme kanseri insidansını artırabileceği ifade edilmiştir (Dieterich ve ark., 2014). Darbre (2001) makalesinde ülkelere göre değişiklik göstermekle birlikte, kadınlarda memenin üst dış kadranındaki kanser insidansının yıllara göre artmakta olduğuna dikkat çekmiş ve bu oranın Lane-Claypon (1926) tarafindan \%30.9, Azzena ve arkadaşları (1994) tarafindan \%60.7 olarak saptandığ1 belirtilmiştir(Lane-Claypon, 1926; Azzena ve ark., 1994; Darbre, 2001).

Darbre (2005) çalışmasında meme kanserinin üst dış kadranda görülmesi ile aksiller bölgeye uygulanan deodorant kullanımı arasında pozitif bir sonuç bulunmuştur. Darbre (2005), çalışmasında 1979-2000 yılları arasındaki İngiltere ve Galler Ülkesi'nde memenin üst dış kadranında görülen meme kanseri insidansını incelemiş, çalışma sonucunda insidansın 1979'da \%47,9'dan, 2000 yıllında \%53,3'e kadar arttı̆̆ını belirlemiştir (Darbre, 2005b). Lee (2005) ise, meme kanseri üzerinde İngiltere'de yaptı̆̆ araştırmada, memenin üst dış kadranındaki malign meme kanseri görülme oranını \%62 olarak saptamıştır. Literatürde, memenin üst dış kadranındaki kanserlerin görülme sıklığının meme kadranlarının içerdiği meme dokusuna paralel olarak artış gösterdiği de belirtilmektedir (Darbre, 2005b; Rageth, 2005; Ünal, 2003).

Ülkemizdeki Sağlık Bakanlı̆̆ı’nın meme kanseri ile ilgili verilerine baktığımızda ise; meme kanserinin kadınlarda görülme insidansının 1995 yılında yüz binde 23.5, 2009 yılında yüz binde 40.6 olduğu, meme kanserinin kadınlar arasında görülen 10 kanser tipi içerisinde ilk sırada yer aldığ1 görülmektedir(T.C. Sağlık Bakanlığ1, 1996;Başara, Güler\&Yentür, 2014). Ülkemizdeki tüm meme kanseri vakaları içerisinde memenin üst dış kadranında görülen kanser insidansına ilişkin bilgilere ulaşılamamakla birlikte, Haydaroğlu ve arkadaşlarının (2005), 3897 meme kanserli olgu üzerinde yaptıkları çalışmada, memenin üst dış kadranındaki kanser insidansını \%37.8 (en yüksek); Kılıç ve arkadaşlarının (2003) ise meme kanseri tanısı ile izlenen 712 bayan hasta üzerinde yaptıkları çalışmada tümörün, hastaların \%63.2'sinin sağ, \%56.1'inin de sol memesinin üst dış kadranında lokalize olduğunu saptadıkları dikkati çekmektedir.

Koltuk altı kozmetik ürünlerin sadece mekanik etkisi dışında ek olarak kimyasal bileşenleri nedeni ile de meme kanserine neden olabileceğini gösteren çalışmalar bulunmaktadır(Darbre, 2001; Darbre, 2003; Darbre ve ark., 2004). Darbre (2005), 'Alüminyum, antiperspirantlar ve meme kanseri' konulu makalesinde, koltuk altı kozmetik ürünlerde aktif antiperspirant ajan olarak yüksek dozda (\%15-25) alüminyum klorid, alüminyum klorhidrat, alüminyum zirkonyum klorhidrat glisin gibi alüminyum tuzlarının bulunduğunu, ancak bu tuzların geniş ölçüde, uzun vadede ve fazla kullanıma bağlı olarak meme üzerindeki etkilerinin neler olduğunun tam olarak bilinmediğini vurgulamaktadır(Darbre, 2005a).

Literatüre bakıldığında, koltuk altı ve antiperspirant deodorantların içinde yer alan phydroxybenzoik asit (paraben) esterlerinin ve alüminyum tuzlarının östrojenik aktivitelerinin olduğu, buna bağlı olarak da meme kanseri riskini arttırıcı rolü oldukları tartışılmaktadır(Darbre, 2005a; Harvey\&Everett, 2004; Dieterich ve ark., 2014). Skelton ve arkadaşları (1993) yaptıkları çalışmada, alüminyum zirkonyum komplekslerinin, antiperspirant deodorantların uygulandığ1 alanlarda granüloma gelişimine neden olduğunu belirtmişlerdir.

McGrath (2003), 437 meme kanseri olan bayan üzerinde yaptı̆̆1 araştırmada, koltuk altı bölgeyi tıraş ettikten sonra sıklıkla alüminyum içeren antiperspirant deodorant kullanan bayanların daha erken yaşta meme kanseri tanısı aldığını saptamıştır. McGrath (2003) çalışmasında, meme kanseri tanısı konan kadınların yaş ortalamasını, koltuk altı kozmetik ürünleri kullanan hastalarda 53 yaş, hiç kullanmayan hastalarda ise 67.3 olarak belirlemiştir. Çalışmada ayrıca, 16 yaşından önce koltuk altı 
GülerDemir, S., \&Bulut, H. (2016). Terlemeyiönleyenkozmetikürünler meme kanserine mi nedenoluyor?International Journal of Human Sciences, 13(1), 309-317. doi: $10.14687 /$ ijhs.v13i1.3345

kozmetik ürünleri kullanan hastaların meme kanseri tanısı konma yaş ortalamasının 46.3, ürünleri kullanmayan bayanlarda ise 67.3 olduğu saptanmıştır.

McGrath, 2009 yılında yayınladığı bir başka çalışmasında, başta Afrikalı ve Amerikalı genç kadınlarda olmak üzere, tüm dünyada antiperspirant deodorant kullanma sıklığının arttığını, antiperspirant deodorantların alüminyum tuzları içerdiğini, bu tuzların da ter bezlerinde tıkanıklı̆̆a neden olduğunu belirtmektedir. Aynı çalışmada, koltuk altındaki apokrin ter bezlerinin östrojen, testosteron ve çok sayıla androjen içerdiği, bezlerdeki tıkanmanın bu hormonların birikmesine neden olduğu, bunun da gelişmekte olan meme dokusunun uzun vadede hormonlara maruz kalmasına ve meme kanseri riskinin artmasına neden olabileceği vurgulanmaktadır (McGrath, 2009). Ancak, her iki çalısmasında da McGrath, kadınlarda meme kanseri ile koltuk altı deoodorant kullanma alışkanlığı arasında kesin bir ilişki olduğunun söylenemeyeceğini, bu gözlemleri de içeren daha ayrıntılı ve vaka kontrollü araştırmalara gereksinim olduğunu vurgulamaktadır (McGrath, 2003; McGrath, 2009).

Darbre ve arkadaşları (2004), insan meme kanseri doku örneklerini inceledikleri başka bir çalışmada ise, bu örneklerde p-hydroxybenzoik asit esterlerinin varlığına rastlamışlardır. Yapılan çalışmada, bu esterlerin östrojenik aktiviteleri olduğu, düşük konsantrasyonlarda bile östrojen reseptörlerine bağlanarak istenmeyen etkilere neden olabileceği belirlenmiştir(Darbre ve ark., 2004). Literatürde östrojenin meme kanserinde majör bir etiyolojik faktör olduğu, bu nedenle de özellikle meme kanseri olan hastaların birinci derece yakınlarının, adölesan dönemdeki bayanların östrojenik etkisi olan kimyasal maddelere maruz kaldıklarında büyük bir risk taşıdıkları belirtilmektedir (Harvey, 2003; Harvey\&Everett, 2004). P-hydroxybenzoik asit esterlerin östrojenik aktiviteleri zayıf olmakla beraber, koltuk altı kozmetik ürünlerin ve bu esterleri içeren diğer ürünlerin uzun süre kullanımı sonucunda etkileri görülebilmektedir. Bir başka çalışmada, alüminyumun genotoksik bir madde olduğu, DNA üzerinde değişikliklere ve epigenetik etkilere neden olabildiği, bunun da meme kanserinde potansiyel bir rol oynayabileceği belirtilmektedir(Lee, 2005).

Yukarıda belirtilen çalışmaların aksine, literatürde koltuk altı ve antiperspirant deodorantların meme kanseri için risk faktörü olmadığını belirten çalışmalar da bulunmaktadır (Fakri, Al-Azzawi, \& AlTawil, 2006; Mirick, Davis, \& Thomas, 2002; Rageth, 2005). Lee (2005), meme karsinomunun memenin üst dış kadranında daha sık görülmesinin memenin üst dış kadranında büyük oranda meme dokusu bulunmasına bağlı olabileceğini belirtmektedir (Lee 2005).

Mirick ve arkadaşları (2002), 20 - 74 yaş arası kadınlarda meme kanseri riski ile koltuk altı terlemeyi önleyici ürün kullanımı arasındaki ilişkiyi araştırmak amacıyla toplum tabanlı vaka kontrol çalışması yapmışlardır. Araştırmaya katılan vaka grubundaki meme kanseri olan $(\mathrm{n}=813)$ ve kontrol grubundaki ( $\mathrm{n}=793$ ) meme kanseri olmayan bayanlar, düzenli antiperspirant kullanımı, aşırı antiperspirant kullanımı ve koltuk altı tıraşından sonraki bir saat içerisinde antiperspirant kullanımı yönünden incelenmiştir. Araştırmadan elde edilen bulgularda bu yöntemlerden en az birini kullanan vaka ve kontrol grubundaki bireyler arasında, antiperspirant deodorant kullanımı ile meme kanseri arasında anlamlı bir ilişki olmadığı saptanmıştır(Mirick ve ark., 2002).

Fakri ve arkadaşları (2006) da, meme kanserinin risk faktörleri ile meme kanseri gelişimi arasında ilişki olup olmadığını araştırdıklanı çalışmalanında, antiperspirant deodorant kullanımı ile meme kanseri gelişimi arasında ilişki olmadığını, aile öyküsünün ve oral kontraseptif kullanımının meme kanseri gelişiminde daha etkili olduğunu belirlemişlerdir.

Demir, Bulut, Dal, Elbaş ve Kurukahvecioğlu (2009), meme kanseri nedeniyle ameliyat olan 62 hastayı taşıdıkları risk faktörleri yönünden retrospektif olarak incelemişler ve hastalardan sadece \%21'inin tanı almadan önce koltuk altı (pudralı) deodorant kullandıklarını saptamışlardır.

Exley ve arkadaşları ise (2007), mastektomi ameliyatı yapılan 17 hastanın meme dokusu örneklerini inceledikleri çalşmada, memenin aksilla ve lateral bölgelerindeki örneklerde alüminyum düzeyinin diğer bölgedelere oranla anlamlı derecede yüksek ( $\mathrm{p}=0.033)$ olduğunu saptamışlardır. Çalışmada, 
GülerDemir, S., \&Bulut, H. (2016). Terlemeyiönleyenkozmetikürünler meme kanserine mi nedenoluyor?International Journal of Human Sciences, 13(1), 309-317. doi: $10.14687 /$ ijhs.v13i1.3345

alüminyum düzeyindeki artışın koltuk altı antiperspirant deodorantların kullanımı ile ilgili doğrudan kesin bir kanıt olmadığı, tümör dokusunun biyokimyası ile ilgili de olabileceği ifade edilmektedir (Exley ve ark., 2007). Harvey ve Everett (2004), Darbre ve arkadaşlarının (2004) çalışmasındaki bulguların p-hydroxybenzoik asit esterlerinin tek başına meme kanserine neden olduğu ile ilgili bir kanıt göstermediğini, ancak önemli bir faktör olduğunu, meme kanseri ile ilişkisini gösteren bazı soruları beraberinde getirdiğini ve bunların araştırılması gerektiğini belirtmektedir (Harvey\&Everett, 2004). Bu bulguyu destekler şekilde Monello, Ligi ve Canale (2013) tarafindan yapılan bir çalışmada, kanserli bireylerde memenin mikro-çevresinde farklı düzeylerde alüminyum, oksidatif ürünler ve inflamatuar faktörler olduğu, bunların düzeylerinin sağlıklı bireylere oranla anlamlı derecede daha yüksek olduğu belirlenmiştir. Aynı çalışmada, memenin mikro-çevresindeki alüminyum birikiminin oksidatif/inflamatuarfenotip meme hücreleri için bir risk faktörü olabileceği vurgulanmaktadır (Monello ve ark, 2013).

Namer, Luporsi, Gligorov, Lokiec ve Spielmann (2008) ise, koltuk altı ve antiperspirant deodorant kullanımı ile meme kanseri arasında bir ilişki olup olmadığını araştırmak amacıyla sistematik olarak PubMed veri tabanındaki konu ile ilgili yapılan yayınları araştırmışlardır. Araştırmanın sonucunda konu ile ilgili 59 çalışma bulunmuş ve çalışmaların 19'u derinlemesine inceleme yapılmak amaciyla seçilmiştir. Yapılan inceleme sonucunda, araştırmaların çoğunun yönteminin sağlıklı olmadığ1 ve bu çalışmaların koltuk altı/antiperspirant deodorant kullanımı ile meme kanseri arasında ilişki olduğuna dair kanıta dayalı bilimsel sonuçlar ortaya koymadıkları belirlenmiştir (Namer ve ark., 2008).

Benzer şekilde, Hardefeldt, Edirimanne ve Eslick (2013) tarafindan MEDLINE, EMBASE, PubMed, Current Contents Connect ve Google Scholar (1950-2012) arama motorlarını kullanarak yapılan sistematik taramada, sadece meme kanseri tanısı almamıs kadınlarla yapılan vaka kontrol çalışmaları incelenmiş ve yalnız 2 çalışma bu kriterlere uygun bulunmuştur. Bu iki çalışmada da koltuk altı kozmetik ürün kullanımının meme kanserini arttırmadığı belirtilmiştir (Hardefeldt ve ark., 2013). Benzer şekilde yapılan farklı çalşmalarda, hem meme kanseri hem de normal dokuda alüminyum konsantrasyonu benzer bulunmuş (Rodriques-Peres ve ark., 2013), bunun yanı sıra koltuk altı kozmetik ürün kullanmayan kadınların meme dokusunda da parapen ve alüminyum düzeyleri olduğu belirlenmiştir (Barr, Metaxas, Harbach, Savoy ve Darbre, 2012).

Bununla birlikte meme kanseri gelişimi üzerinde deodorant kullanımının etkisi hem bilimsel olarak, hem de toplumsal olarak oldukça ilgi çeken bir konudur. Bugüne kadar yapılan çalışmalarda deodorant kullanımının zararlı etkileri üzerine ortaya çıkarılan kanıtların yeterli ve etkin olmadığı görülmektedir. Darbre, Mannelo ve Exley(2013) meme dokusunda alüminyum konsantrasyonunun ölçülmesinde hem in vivo, hem de in vitro çalışmalara ihtiyaç olduğunu ve ayrıca alüminyum etkisi için spesifik biyomarkırların tanımlanması gerektiğini belirtmişlerdir. Farasani ve Darbre (2015), alüminyumun sadece DNA hasarı yapmadığını, aynı zamanda DNA onarım sistemini tehlikeye düşürdüğünü ve meme karsinogenezi üzerine potansiyel etkisi bulunduğunu belirtmektedir. Günümüzde yapılan çalışmalarda da, bu konuya dikkat çekilerek, alüminyumun meme dokusunda bulunan fizyolojik bir komponent olmadığı, bu nedenle de antiperspirant deodorantlardaki bu metalin konsantrasyonunun azaltılmasının acil bir önlem olduğu vurgulanmaktadır (Pineau, Fauconneau, Sappino, Deloncle ve Guillard, 2014).

\section{Sonuç ve Öneriler}

Sonuç olarak, günlük hayatımızda kullanımı giderek artan antiperspirant deodorantların meme kanserine neden olup olmadığı konusu, tartışılmaya devam etmesine karşın, bilimsel literatür bu iddiaları yanıtlamada henüz yeterli kanıtlara ulaşamamıştır. Buna karşın sonuçlar, koltuk altı ve antiperspirant deodorantların uzun süre kullanıldığında, içerdikleri p-hydroxybenzoik asit (paraben) esterlerinin ve alüminyum tuzlarının meme üzerine etkilerinin olabileceğini ve bu konunun araştırılması gerektiğine işaret etmektedir. Konu ile ilgili edindiğimiz bilgiler ışığında; 
GülerDemir, S., \&Bulut, H. (2016). Terlemeyiönleyenkozmetikürünler meme kanserine mi nedenoluyor?International Journal of Human Sciences, 13(1), 309-317. doi: $10.14687 /$ ijhs.v13i1.3345

- Ülkemizde antiperspirant kullanım sıklığının belirlenmesi ve vaka kontrol çalışmalarının yapilmas1,

- Antiperspirantların meme dokusu üzerine etkilerinin belirlemeye yönelik vaka kontrol çalışmalarının yapılması,

- Meme kanseri yönünden yüksek risk taşıyan bayanların koltuk altı ve antiperspirant deodorantları kullanırken dikkatli olmas1,

- Tüm sağlık ekibinin bu konuda bilinçlendirilmesi gerektiği düşünülmektedir.

\section{KAYNAKLAR}

Azzena, A.,Zen, T., Ferrara, A., Brunetti, V., Vasile, C., \& Marchetti, M.(1994). Risk factors for breast cancer. Case-control study results. European Journal of Gynaecological Oncology, 15(5): 386-392.

Barr, L., Metaxas, G., Harbach, C.A.J., Savoy, L.A., \& Darbre, P.D. (2012). Measurement of paraben concentrations in human breast tissue at serial locations across the breast from axilla to sternum. Journal of Applied Toxicology, 32, 219-232.doi: 10.1002/jat.1786

Başara, B.B., Güler, C., \&Yentür, G.K. (2014). T.C. Sağhlk Bakanlĭg Sağhlk İstatistikleri Yullh̆ğ 2013. Ankara: Sentez Matbaacilik ve Yayıncilik.

Beji, N.K.,\& Reis N. (2007). Risk factors for breast cancer in Turkish women: a hospital-based case-control study. European Journal of Cancer Care, 16, 178-184. doi: 10.1111/j.13652354.2006.00711.x

Belli, A.K.,\& Ferahman, M. (2011). Meme kanseri epidemiyolojisi ve etiyolojisi. İçinde S. Aydın \& T. Akça (Eds.). Tüm Yönleriyle Meme Kanseri (ss. 27-32). Adana: Adana Nobel Kitabevi.

Darbre, P.D. (2001). Hypothesis: underarm cosmetics are a cause of breast cancer. European Journal of Cancer Prevention, 10, (5):389-393.

Darbre, P.D. (2003). Underarm cosmetics and breast cancer. Journal of AppliedToxicology, 23 (2): 8995. doi: 10.1002/jat.899

Darbre, P.D. (2005a). Aluminium, antiperspirants and breast cancer. Journal of Inorganic Biochemistry, 99 (9): 1912-1919. doi:10.1016/j.jinorgbio.2005.06.001

Darbre, P.D. (2005b). Recorded quadrant incidence of female breast cancer in Great Britain suggests a disproportionate increase in the upper outer quadrant of the breast. Anticancer Research, 25 (3c): 2543-2550.

Darbre, P.D., Aljarrah, A., Miller, W.R., Coldham, N.G., Sauer, M.J., \& Pope, G.S. (2004). Concentrations of parabens in human breast tumours. Journal of Applied Toxicology, 24 (1): 513. doi: $10.1002 /$ jat.958

Darbre, P.D., Mannello, F., \&Exley, C. (2013).Aluminium and breast cancer: Sources of exposure, tissue measurements and mechanisms of toxicological actions on breast biology. Journal of Inorganic Biochemistry, 128, 257-261. doi: 10.1016/j.jinorgbio.2013.07.005

Farasani, A., \&Darbre, P.D.(2015). Effects of aluminium chloride and aluminium chlorohydrate on DNA repair in MCF10A immortalised non-transformed human breast epithelial cells. Journal of Inorganic Biochemistry, 152,186-189.doi: 10.1016/j.jinorgbio.2015.08.003

Demir, S.G., Bulut, H., Dal, Ü., Elbaş, N.Ö., \& Kurukahvecioğlu, O. (2009, Eylül-Ekim). Meme kanseri nedeniyle ameliyat olan hastaların taşıdıkları risk faktörlerinin incelenmesi. Poster bildiri. X. Meme Hastalıkları Kongresi, İzmir.

Dieterich, M., Stubert, J., Reimer, T., Erickson, N., \& Berling, A. (2014).Influence of Lifestyle Factors on Breast Cancer Risk. Breast Care, 9 (6): 407-414. doi:10.1159/000369571 
GülerDemir, S., \&Bulut, H. (2016). Terlemeyiönleyenkozmetikürünler meme kanserine mi nedenoluyor?International Journal of Human Sciences, 13(1), 309-317. doi: 10.14687/ijhs.v13i1.3345

Exley, C., Charles, L.M., Barr, L., Martin, C., Polwart. A., \& Darbre, P.D. (2007). Aluminium in human breast tissue. Journal of Inorganic Biochemistry, 101 (9) : 1344-1346. doi:10.1016/j.jinorgbio.2007.06.005

Fakri, S., Al-Azzawi, A., \& Al-Tawil, N. (2006). Antiperspirant use as a risk factor for breast cancer in Iraq. Eastern Mediterranean Health Journal, 12 (3-4): 478-482.

Hardefeldt, P.J, Edirimanne, S. \& Eslick, G.D. (2013). Deodorant use and breast cancer risk. Epidemiology, 24 (1), 172. doi: 10.1097/EDE.0b013e3182781684

Harvey, P.W. (2003). Parabens, oestrogenicity, underarm cosmetics and breast cancer: a perspective on a hypothesis. Journal of Applied Toxicology, 23 (5):285-288.doi: 10.1002/jat.946

Harvey, P.W.,\& Everett, D.J. (2004). Significance of the detection of esters of p - hidroxybenzoic acid (parabens) in human breast tumors. Journal of Applied Toxicology,24 (1): 1-4.doi: 10.1002/jat.957

Haydaroğlu, A., Dubova, S., Özsaran, Z., Bölükbaşı, Y., Yılmaz, R., Kapkaç, M., \& Özdedeli, E. (2005). Ege Üniversitesinde meme kanserleri: 3897 olgunun değerlendirilmesi. Meme Sağhl̆g Dergisi, 1 (1): 6-11.

International Agency for Research on Cancer (2014, Eylül). Online analysis. http://globocan.iarc.fr/Default.aspx

Jones, J. (2000). Can rumors cause cancer? Journal of the National Cancer Institute, 92 (18): 1469-1471. doi: $10.1093 /$ jnci/92.18.1469

Kılı̧, S., Tezcan, S., Kömürcü, Ş., Özet, A., Çakır, B., Tümerdem, N., ve arkadaşları (2003). GATA Tıbbi Onkoloji bilim dalında meme kanseri tanısı ile izlenen kadın hastaların bazı sosyodemografik ve hastalık özellikleri. Gulbane Tap Dergisi, 45 (2): 189 - 195.

Lane-Claypon, J.E. (1926). A further report on cancer of the breast with special reference to its associated antecedent conditions. Ministry of HealthReports on PublicHealthandMedicalSubjectsno. 32. London: HMSO.

Lee, H.S.A. (2005). Why is carcinoma of the breast more frequent in the upper outer quadrant? A case series based on needle core biopsy diagnoses. The Breast, 14 (2): 151-152. doi:10.1016/j.breast.2004.07.002

McGrath, K.G.(2003). An earlier age of breast cancer diagnosis related to more frequent use of antiperspirants/deodorants and under arm shaving. European Journal of Cancer Prevention, 12 (6): 479-485. doi: 10.1097/01.cej.0000103462.62592.c6

McGrath,K.G.(2009).Apocrine sweat gland obstruction by antiperspirants allowing transdermal absorption of cutaneous generated hormones and pheromones as a link to the observed incidence rates of breast and prostate cancer in the 20th century. Medical Hypotheses, 72 (6) : 665-674. doi:10.1016/j.mehy.2009.01.025

Mirick, D.K., Davis, S., \& Thomas, D.B. (2002). Antiperspirant use and the risk of breast cancer. Journal of the National Cancer Institute, 94 (20): 1578-1580. doi: 10.1093/jnci/94.20.1578

Mannello, F., Ligi, D.,\& Canale M. (2013). Aluminium, carbonyls and cytokines in human nipple aspirate fluids: possible relationship between inflammation, oxidative stress and breast cancer microenvironment. Journal of Inorganic Biochemistry, 128: 250-256. doi: 10.1016/j.jinorgbio.2013.07.003

Namer, M., Luporsi, E., Gligorov, J., Lokiec, F., \&Spielmann, M. (2008). The use of deodorants/ antiperspirants does not constitute a risk factor for breast cancer. Bulletin du Cancer, 95 (9): 871-880. doi : 10.1684/bdc.2008.0679

Onat, H.,\& Başaran, M. (2003). Meme kanseri risk faktörleri ve korunma. İçinde E. Topuz, A. Aydıner, \& M. Dinçer (Eds.). Meme Kanseri (ss.90-107). İstanbul: Nobel Tip Kitabevleri.

Özmen V. (2009). Meme hastalıklarının cerrahi tedavi kalitesi nasıl yükseltilebilir? Meme Sağh̆ğ Dergisi, 5 (3);119-121.

Özmen V. (2013). Türkiye’de Meme Kanseri. Türkiye Klinikleri Genel Cerrabi Özel Dergisi, 6 (2):1-6. 
GülerDemir, S., \&Bulut, H. (2016). Terlemeyiönleyenkozmetikürünler meme kanserine mi nedenoluyor?International Journal of Human Sciences, 13(1), 309-317. doi: 10.14687/ijhs.v13i1.3345

Pineau, A., Fauconneau, B., Sappino, A.P., Deloncle, R. \&Guillard, O. (2014). If exposure to aluminium in antiperspirants presents health risks, its content should be reduced. Journal of Trace Elements in Medicine and Biology, 28 (2), 147-150.doi: 10.1016/j.jtemb.2013

Rageth, C.J. (2005). One step forward in proving, that underarm cosmetics do not cause breast cancer. The Breast, 14 (2): 85-86. doi:10.1016/j.breast.2004.08.010

Rodrigues-Peres, R.M., Cadore, S., Febraio, S., Heinrich, J.K., Serra, K.P., Derchain, S.F., ...Sarian, L.O. (2013). Aluminum concentrations in central and peripheral areas of malignant breast lesions do not differ from those in normal breast tissues. BMC Cancer, 13, 104.doi:10.1186/1471-2407-13-104

Sezer, H., Yılmaz, M., Gurler, H., \& Koyuncu, A. (2011) Breast cancer risk factors in Turkey: a hospital-basedcase-control study. Asian Pacific Journal of Cancer Prevention, 12 (9), 2317-2322.

Skelton, H.G., Smith, K.J., Johnson, F.B., Cooper, C.R., Tyler, W.F., \&Lupton, G.P.(1993). Zirconium granuloma resulting from an aluminum zirconium complex: a previously unrecognized agent in the development of hypersensitivity granulomas. Journal of the American Academy of Dermatology, 28 (5Pt2): 874-876.

T.C.Sağlık Bakanlığı. (1997). Sağhlk İstatistikleri 1996. Ankara: Türkiye Cumhuriyeti Sağlık Bakanlığ1 Araşturma Planlama ve Koordinasyon Kurulu Başkanlığı.

Ünal, M. (2003). Meme kanserinde klinik bulgular, evreleme, biyopsi. İçinde E. Topuz, A. Aydıner,\& M. Dinçer (Eds.). Meme Kanseri (ss. 124-131). İstanbul: Nobel Tip Kitabevleri.

\section{Extended English Abstract}

Incidence of breast cancer has been gradually increasing in the recent years (Beji \& Reis, 2007; Özmen, 2009; Sezer, Yllmaz, Gurler, \& Koyuncu, 2011; Özmen, 2013; International Agency for Research on Cancer,2014). Epidemiological studies indicate that most of the breast cancers $(90 \%)$ exist due to environmental exposure, and western lifestyle and culture in particular play an important role; however the agents that cause breast cancer have not yet been clearly identified (Darbre, 2001; Onat ve Başaran 2003). Current studies report that mutations in the BRCA1 and BRCA2, which are the tumor-suppressor genes, cause breast cancer (Darbre 2001; Onat \& Başaran 2003; Belli \&Ferahman, 2011). Breast cancer existence in a family is effective in a ratio of $5 \%$ to $10 \%$. Early menarche, late menopause, nulliparity, late primigravidity, use of oral contraceptive pills, and hormone replacement therapy are the defined risk factors related to breast cancer. Diet, physical activity, smoking and alcohol use are the other factors that mildly increase the risk of breast cancer (Darbre 2001; Beji \& Reis, 2007; Sezer ve ark., 2011; Dieterich, Stubert, ReimeriEricson, \&Berling, 2014). However other agents that cause breast cancer have not been discovered yet, and it is reported that all the identified etiological factors correspond to only $40 \%$ of the total reasons that lead to breast cancer (Darbre, 2001; Belli \&Ferahman, 2011). Use of underarm cosmetic products is shown is identified in published researches to be one of the agents that cause breast cancer development.

Today, underarm and antiperspirant deodorants are extensively consumed cosmetic products to prevent sweating. Axillary deodorants are in stick, roll-on and cream-type formulas, the contents of which include antimicrobial preservatives ( $\mathrm{p}$-hydroxybenzoic acid esters). These antimicrobial preservatives avoid sweating odor, by preventing bacterial growth on the skin surface (Darbre, 2001). Aluminum salts included in the antiperspirant deodorants combine with the axillary damaged cells, and these compounds precipitate to form a physical block by plugging the ducts of the axillary sweat glands; sweat is thus prevented from being released through the pores in the skin (Darbre, 2001; Darbre, 2005a). In addition, aluminum salts remaining on the skin surface continue their actions until being removed by soap or shampoo (Darbre, 2005a). 

Journal of Human Sciences, 13(1), 309-317. doi: $10.14687 /$ ijhs.v13i1.3345

An increasing use of these products has revived the claims of an increased breast cancer risk. While discussing these claims, drawn attention at society, in the popular press and on the Internet, it has been discussed in the scientific literature simultaneously. Today, increased use of such products and its relevance with the increased incidence of breast cancer which mostly involves the upper outer quadrant of the breast has raised a question of increased risk of breast cancer.

In this article, we investigated whether there is a relationship between underarm cosmetic products and breast cancer development in the light of literature data. The study was prepared by using Google Academic, Medline and Pubmed search engines. The phrase, 'Deodorant and breast cancer or breast neoplasm or breast carcinoma' was used as the keywords. The number of articles that could be reached in Google Academic, Medline and Pubmed were 2960, 83, and 11, respectively. A systematic search was not performed, and only basic studies on this subject were evaluated.

Review of the literature has shown several studies showing the relationship between underarm cosmetic products and breast cancer, as well as the opposites. Many studies have demonstrated that antiperspirant deodorants are often used near the breasts, increasing the risk of breast cancer which involves the upper outer quadrant of the breast. In addition to the mechanical effects of underarm cosmetic products, such products may cause breast cancer due to their chemical compounds, as suggested by several studies. Some authors have discussed the estrogenic activities of $\mathrm{p}$ hydroxybenzoic acid esters (paraben) and aluminum salts in the antiperspirant deodorants, thereby leading to an increased risk of breast cancer.

On the other hand, some authors have suggested that underarm and antiperspirant deodorants do not contribute to the increased risk of breast cancer. The cancer involving the upper outer quadrant of the breast has been attributed to denser breast tissue of the upper outer quadrant. Also, some reported no significant relationship between the use of antiperspirant deodorants and breast cancer development, although use of such cosmetic products may be a pivotal risk factor of the disease and that further case-control studies are required.

As a conclusion, effects of underarm and antiperspirant deodorants on the development of breast cancer have not been effectively determined and proven in the literature. Instead, results indicate that p-hydroxybenzoic acid esters (parabens) and aluminum salts included in underarm and antiperspirant deodorants, may affect breasts in the case of long-term use, and further studies are needed on this subject. In the light of these data,

- The rate of use of antiperspirant deodorants in Turkey should be identified.

- Further case-control studies should be conducted to investigate the possible effects of antiperspirant deodorants on the breast tissue.

- High-risk women should be instructed to cautiously use underarm and antiperspirant deodorants.

- Health care professionals should be trained on the use of underarm and antiperspirant deodorants and breast cancer development. 